\title{
Effect of allogeneic blood transfusion on levels of IL-6 and sIL-R2 in peripheral blood of children with acute lymphocytic leukemia
}

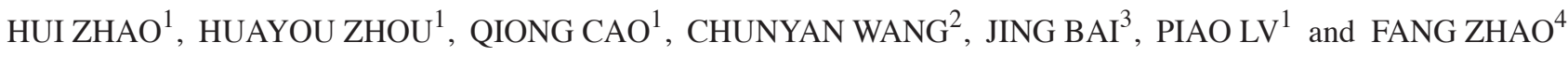 \\ Departments of ${ }^{1}$ Blood Transfusion, ${ }^{2}$ Clinical Laboratory, ${ }^{3}$ Pediatrics and ${ }^{4}$ Stomatology, \\ Nanfang Hospital, Southern Medical University/The First School of Clinical Medicine, \\ Southern Medical University, Guangzhou, Guangdong 510515, P.R. China
}

Received October 19, 2017; Accepted May 10, 2018

DOI: $10.3892 / \mathrm{ol} .2018 .8760$

\begin{abstract}
Effect of allogeneic blood transfusion on the expression of interleukin-6 (IL-6) and soluble interleukin-2 receptor (sIL-2R) in peripheral blood of children with acute lymphoblastic leukemia (ALL) was investigated. A total of 91 ALL children admitted to Nanfang Hospital from June 2014 to January 2017 were selected as the study group. Patients were randomly divided into allogeneic blood transfusion group $(n=38)$ and non-transfusion group $(n=53)$. In addition, a total of 64 healthy children were also selected from June 2014 to January 2017 as the control group. Patients in allogeneic blood transfusion group were transfused with red blood cell suspension and machine-collected platelets, while patients in non-transfusion group were not treated with blood transfusion. Peripheral venous blood was collected before and at 4, 8 and 12 weeks after blood transfusion to prepare serum. Serum IL-6 and sIL-2R levels were measured by enzyme-linked immunosorbent assay (ELISA). Before transfusion, serum levels of IL-6 and sIL-2R were significantly lower in the study group than those in control group $(\mathrm{p}<0.05)$, and no significant differences in serum levels of IL-6 and sIL-2R were found between the allogeneic blood transfusion and non-transfusion group. After transfusion, serum levels of IL-6 and sIL-2R were stable for 12 weeks in the non-transfusion group, while IL-6 and sIL-2R levels were significantly increased in the allogeneic blood transfusion group. The results showed that serum level of IL-6 and sIL-2R was increased in ALL patients with allogeneic blood transfusion, which resulted in reduced antibody production and decreased cellular immunity. The
\end{abstract}

Correspondence to: Dr Fang Zhao, Department of Stomatology, Nanfang Hospital, Southern Medical University/The First School of Clinical Medicine, Southern Medical University, 1838 Guangzhou Avenue North, Guangzhou, Guangdong 510515, P.R. China E-mail: zhaof2283041@163.com

Key words: allogeneic blood transfusion, acute lymphoblastic leukemia, immunosuppression, interleukin-6, soluble interleukin-2 receptor patients had low immunity, and attention should be paid on the pathogen infection prevention.

\section{Introduction}

Acute lymphoblastic leukemia (ALL) mainly occurs in children aged 3-7 years. The abnormal proliferation of B- or T-type mature lymphocytes can inhibit normal hematopoietic function, resulting in fever, leukocytosis, decrease in levels of platelet and neutrophil, eventually leading to anemia, then primitive cells invaded into extramedullary tissue, causing hepatosplenomegaly and a series of lesions $(1,2)$. With the continuous improvement of diagnosis method and chemotherapy, the 5-year survival rate of ALL children has been increased to $80 \%$. ALL has become one of the malignant tumors with the highest cure rate. But effective treatments are still lacking for special subtypes and high risk cases. In addition, the application of chemotherapy is challenged by the serious complications and high recurrence rate caused by toxicity and side-effects (3-5). However, chemotherapy is still the preferred treatment, especially for child patients.

Allogeneic blood transfusion has now become an important radical treatment for ALL. It will lead to a series of complications, and even death if graft vs. host disease occurs (6). Blood from donor with blood relationship is preferred, but blood from donor without blood relationship is also allowed to be used in allogeneic blood transfusion (7). However, studies have shown that allogeneic blood transfusion can inhibit recipient's immune function, which in turn increase postoperative infection, and promote tumor growth, metastasis and recurrence (8). Studies have shown that, after allogeneic blood transfusion, the number of $\mathrm{CD}^{+} \mathrm{T}$ cells would be reduced, and IL-2 level would be decreased. IL-2 is an essential factor for the activation of $\mathrm{B}, \mathrm{CD}^{+} \mathrm{T}$ and NK cells, and the decrease in the level of IL-2 can lead to immunosuppression (9). Interleukin-6 (IL-6) is also known as B-cell differentiation factor. IL-6 is secreted by monocytes and activated Th cells, and its role is to maintain the growth and differentiation of B cells, stimulate the production of immunoglobulin, and induce IL-2 expression, so as to participate in multiple processes of inflammatory response $(10,11)$. Activated $\mathrm{T}$ cells and other monocytes can secrete soluble interleukin-2 receptor (sIL-2R), a low-affinity receptor for IL-2 that is involved in the regulation of 
IL-2-mediated lymphocyte activation (12). sIL-2R is recognized as a marker of multiple lymphomas and blood tumors. Level of sIL-2R in blood is closely related to the prognosis of patients with hematological malignancies (13). It has been reported that high levels of sIL-2R in the blood of patients with lymphoma suggest poor prognosis. The possible explanation is that sIL-2R may bind to serum-free IL-2 to reduce the function of IL-2 in regulating cellular immunity $(14,15)$.

In this study, ALL children received allogeneic blood transfusion therapy, and serum levels of IL-6 and sIL-2R were detected before and after treatment to analyze the immune status of children after transfusion and to predict the prognosis. Our study provided references for follow-up studies.

\section{Materials and methods}

General information. A total of 91 children with ALL admitted to Nanfang Hospital of Southern Medical University (Guangzhou, China) from June 2014 to January 2017 were selected as the study group. Inclusion criteria: i) with ALL confirmed by bone marrow cell morphology, cytochemistry, cytogenetics and immunophenotyping; ii) children aged 3-12 years; and iii) parents signed informed consent. Exclusion criteria: i) combined with lung, kidney, liver and other functional abnormalities; and ii) with severe mental dysfunction. Among 91 patients, there were 43 males and 48 females, and the age ranged from 3 to 12 years with an average age of $6.98 \pm 1.45$ years. Patients were randomly divided into allogeneic blood transfusion group $(n=38)$ and non-transfusion group $(n=53)$. Allogeneic blood transfusion group included 17 males and 21 females, the age ranged from 3 to 12 years with an average age of $6.98 \pm 1.45$ years. The non-transfusion group included 26 males and 27 females, and the age ranged from 3 to 12 years with an average age of $7.09 \pm 1.42$ years. No significant differences in general information were found between the two groups. In addition, a total of 64 healthy children who attend physical examination in the hospital were also selected from June 2014 to January 2017 as the control group. None of the children had history of recent infection. The control group included 30 males and 34 females, and the age ranged from 3 to 12 years with an average age of $6.71 \pm 1.39$ years. No significant differences in general information were found between the study and control groups. The study was approved by the Ethics Committee of Nanfang Hospital and informed consents were signed by the guardians of the patients.

Methods. Hepatitis virus, cytomegalovirus and herpes virus and other infections were not detected in the donors, and the donors had the blood type O. Cross-matching was performed before transfusion to ensure the compatibility between the recipient and donor. Lymphocytes were separated from blood using the Baxter CS-3000 Plus Blood Cell Separator (Baxter, Deerfield, IL, USA) to obtain erythrocyte suspension and platelets. Patients in the allogeneic blood transfusion group were transfused with allogeneic erythrocyte suspension and platelet (3.5 U), as previously reported (16). Blood transfusion was not performed in the non-transfusion group. Peripheral venous blood $(3 \mathrm{ml})$ was extracted from each participant before and at 4,8 and 12 weeks after blood transfusion. Blood samples were centrifuged $(2,010 \mathrm{x}$ g) for 8-12 min to separate
Table I. Serum levels of IL-6 and sIL-2R in the study and control group (mean \pm standard deviation).

\begin{tabular}{lccc}
\hline Groups & Cases & IL-6 $(\mathrm{U} / \mathrm{ml})$ & sIL-2R $(\mathrm{pg} / \mathrm{ml})$ \\
\hline Study & 91 & $237.49 \pm 68.42$ & $1.28 \pm 0.34$ \\
Control & 64 & $474.23 \pm 121.65$ & $7.32 \pm 2.19$ \\
t-test & & 101.05 & 22.14 \\
P-value & & $<0.05$ & $<0.05$ \\
\hline
\end{tabular}

IL-6, interleukin-6; sIL-2R, soluble interleukin-2 receptor.

serum. Serum was stored at $-20^{\circ} \mathrm{C}$ before use. Levels of IL-6 and SIL-2R were detected by enzyme-linked immunosorbent assay (ELISA) using kits (human IL-6 ELISA kit, cat. no. BMS213-2TEN; human sIL-2R kit, cat. no. BMS212-2; Thermo Fisher Scientific, Inc., Waltham, MA, USA). OD values as $450 \mathrm{~nm}$ were measured using a microplate reader (Bio Rad Laboratories, Inc., Hercules, CA, USA).

Observational measurements. i) To observe the changes of serum IL-6 and sIL-2R levels in the study and control group; ii) to observe the changes of serum IL-6 level in the allogeneic blood transfusion and non-transfusion group before and at 4, 8 and 12 weeks after blood transfusion group; iii) to observe the changes of serum sIL-2R level in the allogeneic blood transfusion and non-transfusion group before and at 4 , 8 and 12 weeks after blood transfusion group.

Statistical analysis. SPSS 19.0 software (IBM Corp., Armonk, NY, USA) was used. Measurement data are expressed as the mean \pm standard deviation, and comparisons between the groups were performed by t-test. Enumeration data were expressed as cases, and comparisons between the groups were performed by Chi-square test. Comparisons within the groups were performed by analysis of variance to repeated measurements and the post hoc test was Dunnett's test. $\mathrm{P}<0.05$ was considered to be statistically significant.

\section{Results}

Changes in serum levels of IL-6 and sIL-2R in the study and control group. Before transfusion, levels of serum IL-6 and sIL-2R in the study group were significantly lower than those in control group $(\mathrm{p}<0.05)$ (Table I).

Changes of serum IL-6 levels in the allogeneic blood transfusion and non-transfusion group. There was no significant difference in serum IL-6 levels between the two groups before transfusion ( $p>0.05$ ). Serum IL-6 level was stable in non-transfusion group for 12 weeks. Serum IL-6 level significantly increased at 4 weeks after transfusion in the allogeneic blood transfusion group, and gradually decreased at 8 and 12 weeks after transfusion, but was still significantly higher than the level before transfusion ( $\mathrm{p}<0.05)$. Serum levels of IL-6 were significantly higher in the allogeneic blood transfusion group than in non-transfusion group during 12 weeks after transfusion $(\mathrm{p}<0.01)$ (Table II). 
Table II. Changes of serum IL-6 levels in the allogeneic blood transfusion and non-transfusion group (U/ml).

\begin{tabular}{|c|c|c|c|c|c|}
\hline Groups & Cases & Before transfusion & 4 weeks & 8 weeks & 12 weeks \\
\hline Allogeneic blood transfusion & 38 & $238.42 \pm 49.21$ & $97.42 \pm 38.31^{\mathrm{a}}$ & $62.91 \pm 25.25^{\mathrm{a}, \mathrm{b}}$ & $134.12 \pm 53.21^{\mathrm{a}, \mathrm{c}}$ \\
\hline Non-transfusion & 53 & $236.98 \pm 67.39$ & $229.38 \pm 58.13$ & $241.38 \pm 73.76$ & $225.09 \pm 64.07$ \\
\hline t-test & & 0.37 & 32.86 & 50.19 & 13.03 \\
\hline P-value & & $>0.05$ & 0.001 & $<0.001$ & 0.002 \\
\hline
\end{tabular}

${ }^{\mathrm{a}} \mathrm{P}<0.05$, compared with the level before transfusion within a group; ${ }^{\mathrm{b}} \mathrm{p}=0.042$, compared with 4 weeks after transfusion; ${ }^{\mathrm{c}} \mathrm{p}=0.037$, compared with 4 weeks after transfusion. IL-6, interleukin-6.

Table III. Changes of serum sIL-2R levels in the allogeneic blood transfusion and non-transfusion group (pg/ml).

\begin{tabular}{|c|c|c|c|c|c|}
\hline Groups & Cases & Before transfusion & 4 weeks & 8 weeks & 12 weeks \\
\hline Allogeneic blood transfusion & 38 & $1.30 \pm 0.35$ & $3.91 \pm 1.27^{\mathrm{a}}$ & $3.46 \pm 1.14^{\mathrm{a}, \mathrm{b}}$ & $2.75 \pm 0.87^{\mathrm{a}, \mathrm{c}}$ \\
\hline Non-transfusion & 53 & $1.26 \pm 0.32$ & $1.29 \pm 0.37$ & $1.23 \pm 0.29$ & $1.27 \pm 0.32$ \\
\hline t-test & & 0.57 & 3.69 & 8.64 & 4.43 \\
\hline P-value & & $>0.05$ & 0.037 & 0.008 & 0.005 \\
\hline
\end{tabular}

${ }^{\mathrm{a}} \mathrm{P}<0.05$, compared with the level before transfusion within a group; ${ }^{\mathrm{b}} \mathrm{p}=0.089$, compared with 4 weeks after transfusion; ${ }^{\mathrm{p}} \mathrm{p}=0.043 \mathrm{compared}$ with 4 weeks after transfusion. sIL-2R, soluble interleukin-2 receptor.

Changes of serum sIL-2R levels in the allogeneic blood transfusion and non-transfusion group. There was no significant difference in serum sIL-2R levels between the two groups before transfusion $(p>0.05)$. Serum sIL-2R level was stable in non-transfusion group for 12 weeks. Serum sIL-2R level significantly increased at 4 weeks after transfusion in the allogeneic blood transfusion group, and gradually decreased after that, but was still significantly higher than the level before transfusion $(p<0.01)$. Serum levels of sIL-2R were significantly higher in the allogeneic blood transfusion group than in non-transfusion group during 12 weeks after transfusion $(\mathrm{p}<0.05)$ (Table III).

\section{Discussion}

Childhood ALL is a malignant hematologic disease that seriously affects children's physical and mental health and quality of life. Allogeneic blood transfusion has become another treatment option other than chemotherapy, and the combined use of these two treatments can inhibit the proliferation of lymphocytes, resulting in a better therapeutic effect (16). But allogeneic blood transfusion can suppress the immune function of the recipient (17). IL-6 is an important cytokine that maintains B-cell growth and differentiation and the production of antibodies. In this study, both the serum levels of IL-6 and sIL-2R were lower in the study group than in the control group, which was consistent with the fact that the children with ALL had decreased immunity. The results showed that IL-6 levels in serum were significantly increased after allogeneic blood transfusion. IL-6 levels were gradually decreased at 12 weeks after transfusion, but were still higher than pre-transfusion levels. It is consistent with previous studies which showed levels of IL-6 increased after transfusion (18), indicating that the ability immune system to produce antibodies was reduced.
Therefore, infection should be avoided and antibiotics may be used (19). This study found that sIL-2R levels increased at 4 weeks after transfusion. Although decrease was observed after that, the levels were still higher than pre-transfusion levels. Studies reported that levels of IL-2 in serum of children were decreased after transfusion. IL-2 is one of the most important cytokines that regulates the cellular immune response, which could inhibit the children's cellular immune response (20). One reason for the decrease in IL-2 levels is the elevated sIL-2R levels in cells. sIL-2R can bind to serum IL-2, thereby reducing IL-2-mediated cellular immune responses (21). The above reports are consistent with the findings in our study.

In conclusion, our study showed that allogeneic blood transfusion could increase serum IL-6 and sIL-2R levels in ALL patients, so as to inhibit the children's cellular immune response and reduce the production of antibodies, resulting in low immunity in patients. Changes in the level of two cytokines suggest that attention should be paid on the immune status of children after transfusion, and preventive measures should be given if necessary.

\section{Acknowledgements}

Not applicable.

\section{Funding}

No funding was received.

\section{Availability of data and materials}

The datasets used and/or analyzed during the current study are available from the corresponding author on reasonable request. 


\section{Authors' contributions}

$\mathrm{HZ}$ and $\mathrm{HYZ}$ collected and analyzed the general data of patients. QC prepared the blood sample. CW, JB and PL were responsible for observational measurements. FZ helped with statistical analysis. All authors have read and approved the final manuscript.

\section{Ethics approval and consent to participate}

The study was approved by the Ethics Committee of Nanfang Hospital of Southern Medical University (Guangzhou, China) and informed consents were signed by the guardians of the patients.

\section{Consent for publication}

Not applicable.

\section{Competing interests}

The authors declare that they have no competing interests.

\section{References}

1. Sanders JE, Im HJ, Hoffmeister PA, Gooley TA, Woolfrey AE, Carpenter PA, Andrews RG, Bryant EM and Appelbaum FR: Allogeneic hematopoietic cell transplantation for infants with acute lymphoblastic leukemia. Blood 105: 3749-3756, 2005.

2. Pieters R and Carroll WL: Biology and treatment of acute lymphoblastic leukemia. Pediatr Clin North Am 55: 1-20, ix, 2008 .

3. Izbicki G, Rudensky B, Na'amad M, Hershko C, Huerta M and Hersch M: Transfusion-related leukocytosis in critically ill patients. Crit Care Med 32: 439-442, 2004.

4. Deng $\mathrm{CH}$ and Zhang QP: Leukemia stem cells in drug resistance and metastasis. Chin Med J (Eng1) 123: 954-960, 2010.

5. Bhojwani D and Pui CH: Relapsed childhood acute lymphoblastic leukaemia. Lancet Oncol 14: e205-e217, 2013.

6. Pui C-H, Gaynon PS, Boyett JM, Chessells JM, Baruchel A, Kamps W, Silverman LB, Biondi A, Harms DO, Vilmer E, et al: Outcome of treatment in childhood acute lymphoblastic leukaemia with rearrangements of the 11q23 chromosomal region. Lancet 359: 1909-1915, 2002.

7. Tzounakas VL, Seghatchian J, Grouzi E, Kokoris S and Antonelou MH: Red blood cell transfusion in surgical cancer patients: Targets, risks, mechanistic understanding and further therapeutic opportunities. Transfus Apheresis Sci 56: 291-304, 2017.
8. Cata JP, Wang H, Gottumukkala V, Reuben J and Sessler DI: Inflammatory response, immunosuppression, and cancer recurrence after perioperative blood transfusions. Br J Anaesth 110: 690-701, 2013.

9. Koehl U, Sörensen J, Esser R, Zimmermann S, Grüttner HP, Tonn T, Seidl C, Seifried E, Klingebiel T and Schwabe D: IL-2 activated NK cell immunotherapy of three children after haploidentical stem cell transplantation. Blood Cells Mol Dis 33: 261-266, 2004.

10. Tvedt TH, Lie SA, Reikvam H, Rye KP, Lindås R, Gedde-Dahl T, Ahmed AB and Bruserud Ø: Pretransplant levels of CRP and interleukin-6 family cytokines; effects on outcome after allogeneic stem cell transplantation. Int J Mol Sci 17: E1823, 2016.

11. Jordan SC, Choi J, Kim I, Wu G, Toyoda M, Shin B and Vo A: Interleukin-6, a cytokine critical to mediation of inflammation, autoimmunity and allograft rejection: Therapeutic implications of IL-6 receptor blockade. Transplantation 101: 32-44, 2017.

12. Murakami S: Soluble interleukin-2 receptor in cancer. Front Biosci 9: 3085-3090, 2004.

13. Katsuya H, Yamanaka T, Ishitsuka K, Utsunomiya A, Sasaki H, Hanada S, Eto T, Moriuchi Y, Saburi Y, Miyahara M, et al: Prognostic index for acute- and lymphoma-type adult T-cell leukemia/lymphoma. J Clin Oncol 30: 1635-1640, 2012.

14. Goto H, Tsurumi H, Takemura M, Ino-Shimomura Y, Kasahara S, Sawada M, Yamada T, Hara T, Fukuno K, Goto N, et al: Serum-soluble interleukin-2 receptor (sIL-2R) level determines clinical outcome in patients with aggressive non-Hodgkin's lymphoma: In combination with the International Prognostic Index. J Cancer Res Clin Oncol 131: 73-79, 2005.

15. Goto N, Tsurumi H, Goto H, Shimomura YI, Kasahara S, Hara T, Yasuda I, Shimizu M, Murakami N, Yoshikawa T, et al: Serum soluble interleukin-2 receptor (sIL-2R) level is associated with the outcome of patients with diffuse large B cell lymphoma treated with R-CHOP regimens. Ann Hematol 91: 705-714, 2012.

16. Bhojwani D, Yang JJ and Pui CH: Biology of childhood acute lymphoblastic leukemia. Pediatr Clin North Am 62: 47-60, 2015.

17. Pape A, Stein P, Horn O and Habler O: Clinical evidence of blood transfusion effectiveness. Blood Transfus 7: 250-258, 2009.

18. Smolen JS and Maini RN: Interleukin-6: A new therapeutic target. Arthritis Res Ther 8 (Suppl 2): S5, 2006.

19. Soker M, Colpan L, Ece A, Devecioglu C and Haspolat K: Serum levels of IL-1 beta, sIL-2R, IL-6, IL-8, and TNF-alpha in febrile children with cancer and neutropenia. Med Oncol 18: 51-57, 2001.

20. Stachura A, Król R, Poplawski T, Michalik D, Pomianowski S, Jacobsson M, Aberg M and Bengtsson A: Transfusion of intra-operative autologous whole blood: Influence on complement activation and interleukin formation. Vox Sang 100: 239-246, 2011.

21. Yoshida N, Oda M, Kuroda Y, Katayama Y, Okikawa Y, Masunari T, Fujiwara M, Nishisaka T, Sasaki N, Sadahira Y, et al: Clinical significance of sIL-2R levels in B-cell lymphomas. PLoS One 8: e78730, 2013.

(i) $($ This work is licensed under a Creative Commons Attribution-NonCommercial-NoDerivatives 4.0 International (CC BY-NC-ND 4.0) License. 